\title{
KNOWLEDGE AND PREVENTION PRACTICES OF HAND, FOOT AND MOUTH DISEASE AMONG PARENTS AND CAREGIVERS IN BANDAR PUNCAK ALAM, SELANGOR, MALAYSIA
}

\author{
Nik Nur Hidayah Mansur ${ }^{1}$ and Azwandi Ahmad ${ }^{1}$ \\ ${ }^{1}$ Department of Pharmaceutical Life Science, Faculty of Pharmacy, Universiti Teknologi MARA Selangor, Puncak Alam \\ Campus, 42300 Bandar Puncak Alam, Selangor Darul Ehsan, Malaysia
}

Corresponding author: Azwandi Ahmad

Email: azwandi047@uitm.edu.my

\begin{abstract}
Hand, Foot, and Mouth Disease (HFMD) is mainly caused by Coxsackievirus A16 (CVA16) and human Enterovirus A71 (EVA71). Severe cases of HFMD were reported in Malaysia in 2018, which led to a temporary closing of few nurseries and preschools. A good knowledge and prevention practices is one of the important factors that can effectively decelerate this rapid outbreak of HFMD. Therefore, we conducted a survey to assess current knowledge and prevention practices among parents and caregivers in Bandar Puncak Alam, Selangor. A cross-sectional, questionnaire-based study was conducted on 345 residences of Bandar Puncak Alam, Selangor. It comprised of $77.4 \%(n=267)$ parents and $22.6 \%$ ( $n=78)$ caregivers from different daycares, kindergartens and preschools. The study showed that the majority, $87.2 \%(n=301)$ of Bandar Puncak Alam residents, Selangor have a moderate level of knowledge on HFMD. No significant difference in knowledge was found between parents and caregivers $(p=0.553)$. Age, occupation, level of education, and income of respondents influenced the HFMD knowledge level $(p<0.05)$. Most parents and caregivers know how to prevent HFMD by practising cleaning the children's toys using liquid disinfection, but they are still lacking knowledge on the role of handwashing in preventing HFMD. In conclusion, the lack of prevention practice among parents and caregivers would increase the cases of HFMD. Therefore, a proper education of HFMD should be done to increase the awareness towards the prevention practices to prevent HFMD from reoccurring.
\end{abstract}

Keywords: Hand, Foot and Mouth Disease, Practice, Caregiver, Parents.

\section{INTRODUCTION}

Hand, foot, and mouth disease (HFMD) is a typical benign and common illness among children and infants. It's characterized by rapid ulcerating vesicles in the mouth and lesions, usually vesicular, on the hands and feet. These symptoms caused mainly by Coxsackievirus A16 (CVA16) and human Enterovirus A71 (EV-A71). ${ }^{1,2}$ Other viruses associated with the syndrome are Coxsackievirus A4, A10, and A24, Coxsackievirus $\mathrm{B} 3$, B4, and B5, Cytomegalovirus (CMV), and Enterovirus $18 .^{3}$

In June 2018, the number of cases of HFMD in Malaysia reported by the Ministry of Health of Malaysia $(\mathrm{MOH})$ had increased by $28 \%$, from 21,303 cases in 2017 to 27,296 cases in $2018 .{ }^{4}$ $\mathrm{MOH}$ also reported that 341 pre-schools, daycare centres and kindergartens need to be closed due to the outbreak. ${ }^{4}$ Two nurseries in Labuan was affected ${ }^{5}$ and 44 clusters of HFMD were reported in Sarawak, with 31 cases occurred at private homes, nine clusters involved preschoolers and four at nurseries. All premises had been ordered to be closed under the relevant law in the first three weeks of 2019. ${ }^{6}$ This severe outbreak might be associated to a lack of knowledge and awareness among parents and caregivers. Inadequate preventive research works on HFMD in Malaysia could also be a reason for these increased number of HFMD cases.

As there are unsufficient survey studies of HFMD in Malaysia, outcome from recent studies is needed to gather and update current public knowledge of this disease and subsequently leads to a better awareness and prevention practices among public. Moreover, such studies can give some insight and awareness to the public about the disease and a proper prevention practice can be planned to reduce the incidence rate of HFMD primarily among children. Besides, the $\mathrm{MOH}$ can gather more data on the public knowledge and prevention practices about HFMD in a particular location, especially in suburban area. Therefore we have carried out a study to assess current knowledge and preventive practices among parents and caregivers in Bandar Puncak Alam, Selangor.

The study's objective was to measure the level of knowledge and preventive practices of HFMD among parents and caregivers in Bandar Puncak Alam, Selangor. Besides that, these studies aimed to identify the factors associated with knowledge level and preventive practices of HFMD among both parents and caregivers in this area. 


\section{METHODS}

\section{Study Design and Sampling}

A cross-sectional study with convenience sampling was practiced in this study. The respondents were selected based on their availability to participate in the research study. A self-administered questionnaire was distributed among residences in Bandar Puncak Alam's to assess their knowledge and prevention practices toward HFMD. Ethical approval and written informed consent were obtained before the data collection can be initiated.

Sample Size

The estimation of sample size was calculated using a sample size calculator by Raosoft ${ }^{\oplus} .{ }^{7}$ By considering the study population size, $\mathrm{N}=25,000$ , the minimum total sample size used for this study was 379 respondents.

\section{Inclusive and Exclusive criteria}

This research study included the parents and caregivers of preschools, daycare centres, or kindergartens located in Bandar Puncak Alam, Selangor, age above 18 years old, and the respondent who can understand either English or Bahasa Malaysia.

Parents or caregivers who are absent during the data collection day will be excluded from the study. Married couples without children and does not have any experience with the children and the respondent who refuse to sign the consent form was also excluded from the study.

Data Collection

A self-constructed questionnaire was distributed to the 379 residences of Bandar Puncak Alam, Selangor, from March to May 2019. Before questionnaires distribution, a pilot study was carried out to determine the questionnaire's internal consistency. For the pilot study, 30 parents and caregivers were recruited to answer the items in the questionnaire. The data were entered into SPSS Version 20. The reliability analysis showed that Cronbach's alpha coefficient was 0.7 ; thus it considers a highreliability test.

\section{Instrument}

The questionnaire was designed in dual language, which was English and Bahasa Malaysia. The questionnaire was divided into three sections: section A consisted of demographic characteristics of the respondents, section $B$ consisted of 10 questions related to HFMD knowledge, and section C consisted of 16 questions related to prevention practices toward HFMD.

\section{Data Analysis}

Statistical Package for Social Science (SPSS) version 20 was used to analyze the data. In the pilot study, the test-retest was done, and the reliability test was performed to ensure the questionnaire's reliability. The demographic data were analyzed using descriptive analysis and represented in the form of frequency and percentage. The parametric test and the nonparametric test were used for normal and not normally distributed data respectively. The Chisquare test was used to test the relationship between a demographic characteristic and knowledge level, meanwhile the t-test was used to compare the knowledge of parents and caregivers about HFMD. The level of significance was set up at 0.05 and $95 \%$ confidence interval $(\mathrm{Cl})$ was used.

\section{RESULTS}

\section{Socio-demographic characteristics of the study} population

Out of 379 questionnaires distributed, 345 (91\%) were returned. Therefore, all the analyses were based on 345 residences of Bandar Puncak Alam, Selangor. This was represented by $77.4 \%(n=267)$ parents and $22.6 \%(n=78)$ caregivers from various daycares, kindergartens, and preschools. Next, age group between $31-35$ years old was $22.9 \%$ $(n=79)$ and age group below than 21 was 3.5\% $(n=12)$. Meanwhile, respondents working in private sector was recorded with $39.7 \% \quad(n=137)$ and retired respondent was recorded with $0.3 \%$ $(n=1)$. Besides that, the respondent with university level and no formal education were $64.9 \% \quad(n=224)$ and $0.3 \% \quad(n=1)$ respectively. Respondents with income RM1,001 to RM5,000 was recorded with $61.1 \% \quad(n=211)$ and income more than RM10,000 was recorded with $3.8 \%$ $(n=13)$. Finally, the data from the respondent with $1-2$ children showed $38.3 \%(n=132)$ and more than 6 children was recorded with only $2 \%(n=7)$ (Table 1). 
Table 1: Socio-demographic characteristics of the study population

\begin{tabular}{|c|c|c|}
\hline Variable & Frequency, $\mathrm{n}=345$ & Percentage (\%) \\
\hline \multicolumn{3}{|l|}{ Category } \\
\hline Parent & 267 & 77.4 \\
\hline Caregiver & 78 & 22.6 \\
\hline \multicolumn{3}{|l|}{ Age } \\
\hline$<21$ & 12 & 3.5 \\
\hline $21-25$ & 36 & 10.4 \\
\hline $26-30$ & 36 & 10.4 \\
\hline $31-35$ & 79 & 22.9 \\
\hline $36-40$ & 73 & 21.2 \\
\hline $41-45$ & 61 & 17.7 \\
\hline $46-50$ & 27 & 7.8 \\
\hline$>50$ & 21 & 6.1 \\
\hline \multicolumn{3}{|l|}{ Occupation } \\
\hline Student & 11 & 3.2 \\
\hline Housewife & 50 & 14.5 \\
\hline Self-employed & 46 & 13.3 \\
\hline Government servant & 100 & 29.0 \\
\hline Private sector & 137 & 39.7 \\
\hline Retired & 1 & 0.3 \\
\hline Unemployed & 0 & 0 \\
\hline \multicolumn{3}{|l|}{ Education Level } \\
\hline Primary & 7 & 2.0 \\
\hline Secondary & 113 & 32.8 \\
\hline University & 224 & 64.9 \\
\hline No Formal Education & 1 & 0.3 \\
\hline \multicolumn{3}{|l|}{ Income } \\
\hline < RM 1000 & 49 & 14.2 \\
\hline RM 1001 - RM 5000 & 211 & 61.1 \\
\hline RM 5001 - RM 10000 & 72 & 20.9 \\
\hline > RM 10000 & 13 & 3.8 \\
\hline \multicolumn{3}{|l|}{ Number of Children } \\
\hline 0 & 67 & 19.4 \\
\hline $1-2$ & 132 & 38.3 \\
\hline $3-4$ & 101 & 29.3 \\
\hline $5-6$ & 38 & 11.0 \\
\hline$>6$ & 7 & 2.0 \\
\hline
\end{tabular}

Association between the socio-demographic factors and the knowledge level of HFMD

The study indicated that most of the respondents $(87.2 \%)$ have a moderate knowledge score (between 5 to 9). Only 3.2\% (n $=11$ ) of respondents have a low level of knowledge score (between 1 to 4 ), while $9.6 \%$ $(n=33)$ of them have a high knowledge level (between 10 to 15). A Pearson's chi-square test of independence was performed to determine whether the demographic factors studied are related to the knowledge level. It was demonstrated that age, $X^{2}(7, N=345)=31.674$, $\mathrm{p}<0.05)$, occupation $X^{2}(5, \mathrm{~N}=345)=14.506$, $\mathrm{p}<0.05)$, educational level, $X^{2}(3, \quad N=345)=$ $12.625, p<0.05)$, and income $X^{2}(3, N=345)=$ 33.591, $p<0.05$ ) were associated with the level of knowledge (Table 2). Meanwhile, the category of respondents and the number of children were not associated with the level of knowledge.

\section{Effect of demographic factors to knowledge} score of HFMD

The output from the t-test indicates that there are no significant differences of knowledge score between parents and caregivers, $t(343)=0.653, \mathrm{p}$ $=0.553$. One way ANOVA test showed that differences were evident in the age of the respondent $F(7,337)=4.885, \mathrm{p}<0.05$, with the highest mean was 8.63 for 46 to 50 years old (Figure 1). Occupation of respondents influenced the knowledge score, $F(5,339)=3.785, \mathrm{p}<0.002$ where government servant scored the highest mean with 8.1 (Figure 2). Besides, the education and income of respondents also showed significant effects which $F(3,341)=5.282, \mathrm{p}<0.01$ and $F(3,341)=12.877, \mathrm{p}<0.01$ respectively. The study showed that university respondents and respondents who have income with more than RM10,000 scored the highest mean with 7.82 and 9.15 respectively (Figure 3 and 4 ).

\section{Prevention practice}

Figure 5 shows the prevention practices of parents and caregivers of Bandar Puncak Alam related to HFMD. The most prevention practice toward HFMD among parents and caregivers is "I rarely use soap for handwashing" with a mean of 11.06 , and the least practice is "I wash my hands before feeding my children," with a mean of 6 . 
Malaysian Journal of Public Health Medicine 2021, Vol. 21 (1): 29-36

Table 2: Association between the level of knowledge HFMD and socio-demographic characteristics

\begin{tabular}{|c|c|c|c|c|c|c|c|}
\hline & \multicolumn{2}{|c|}{ Low } & \multicolumn{2}{|c|}{ Moderate } & \multicolumn{2}{|c|}{ High } & \multirow{2}{*}{$\mathrm{p}$-value } \\
\hline & $\mathrm{n}$ & $\%$ & $\mathrm{n}$ & $\%$ & $\mathbf{n}$ & $\%$ & \\
\hline \multicolumn{8}{|l|}{ Category } \\
\hline Parent & 10 & 90.9 & 229 & 76.1 & 28 & 84.8 & \multirow{3}{*}{0.553} \\
\hline Caregiver & 1 & 9.1 & 72 & 23.9 & 5 & 15.2 & \\
\hline Total & 11 & 100 & 301 & 100 & 33 & 100 & \\
\hline \multicolumn{8}{|l|}{ Age } \\
\hline$<21$ & 0 & 0 & 12 & 4.0 & 0 & 0 & \multirow{9}{*}{$<0.0001^{*}$} \\
\hline-25 & 1 & 9.1 & 34 & 11.3 & 1 & 3.0 & \\
\hline $26-30$ & 3 & 27.3 & 29 & 9.6 & 4 & 12.1 & \\
\hline $31-35$ & 4 & 36.3 & 69 & 22.9 & 6 & 18.2 & \\
\hline $36-40$ & 1 & 9.1 & 67 & 22.3 & 5 & 15.2 & \\
\hline $41-45$ & 2 & 18.2 & 51 & 16.9 & 8 & 24.2 & \\
\hline $46-50$ & 0 & 0 & 21 & 7.0 & 6 & 18.2 & \\
\hline$>50$ & 0 & 0 & 18 & 6.0 & 3 & 9.1 & \\
\hline Total & 11 & 100 & 301 & 100 & 33 & 100 & \\
\hline \multicolumn{8}{|l|}{ Occupation } \\
\hline Student & 0 & 0 & 10 & 3.3 & 1 & 3.0 & \multirow{8}{*}{$0.002^{*}$} \\
\hline Housewife & 3 & 27.3 & 45 & 15.0 & 2 & 6.1 & \\
\hline Self-employed & 3 & 27.3 & 41 & 13.6 & 2 & 6.1 & \\
\hline Government servant & 0 & 0 & 84 & 27.9 & 16 & 48.5 & \\
\hline Private sector & 5 & 45.4 & 121 & 40.2 & 11 & 33.3 & \\
\hline Retired & 0 & 0 & 0 & 0 & 1 & 3.0 & \\
\hline Unemployed & 0 & 0 & 0 & 0 & 0 & 0 & \\
\hline Total & 11 & 100 & 301 & 100 & 33 & 100 & \\
\hline \multicolumn{8}{|l|}{ Education Level } \\
\hline Primary & 0 & 0 & 7 & 2.3 & 0 & 0 & \multirow{4}{*}{$0.001^{*}$} \\
\hline Secondary & 7 & 63.6 & 102 & 33.9 & 4 & 12.1 & \\
\hline University & 4 & 36.4 & 191 & 63.5 & 29 & 87.9 & \\
\hline No Formal Education & 0 & 0 & 1 & 0.3 & 0 & 0 & \\
\hline Total & 11 & 100 & 301 & 100 & 33 & 100 & \\
\hline \multicolumn{8}{|l|}{ Income } \\
\hline$<\mathrm{RM} 1000$ & 4 & 36.4 & 44 & 14.6 & 1 & 3.0 & \multirow{6}{*}{$<0.0001^{*}$} \\
\hline RM 1001 - & 5 & 45.4 & 189 & 62.8 & 17 & 51.5 & \\
\hline RM 5000 & & & & & & & \\
\hline RM $5001-$ & 2 & 18.2 & 60 & 19.9 & 10 & 30.3 & \\
\hline $\begin{array}{l}\text { RM } 10000 \\
>\text { RM } 10000\end{array}$ & 0 & 0 & 8 & 2.7 & 5 & 15.2 & \\
\hline Total & 11 & 100 & 301 & 100 & 33 & 100 & \\
\hline \multicolumn{8}{|l|}{ Number of Children } \\
\hline 0 & 0 & 0 & 63 & 20.9 & 4 & 12.1 & \multirow{6}{*}{0.051} \\
\hline $1-2$ & 7 & 63.6 & 115 & 38.2 & 10 & 30.3 & \\
\hline $3-4$ & 3 & 27.3 & 87 & 28.9 & 11 & 33.3 & \\
\hline $5-6$ & 1 & 9.1 & 31 & 10.3 & 6 & 18.2 & \\
\hline$>6$ & 0 & 0 & 5 & 1.7 & 2 & 6.1 & \\
\hline Total & 11 & 100 & 301 & 100 & 33 & 100 & \\
\hline
\end{tabular}

* Significant at the 0.05 level (2-tailed). 


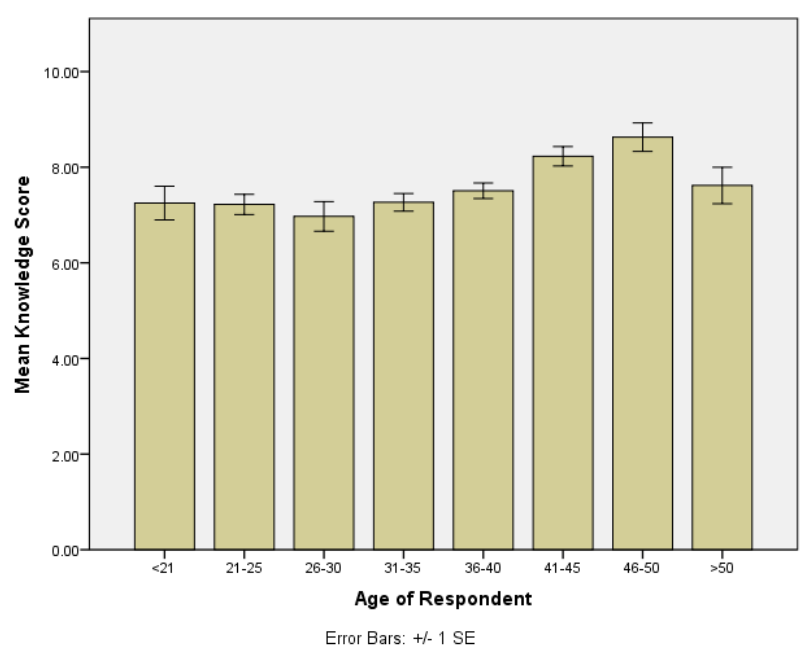

Fig. 1 Influence of respondent's age to the knowledge score of HFMD

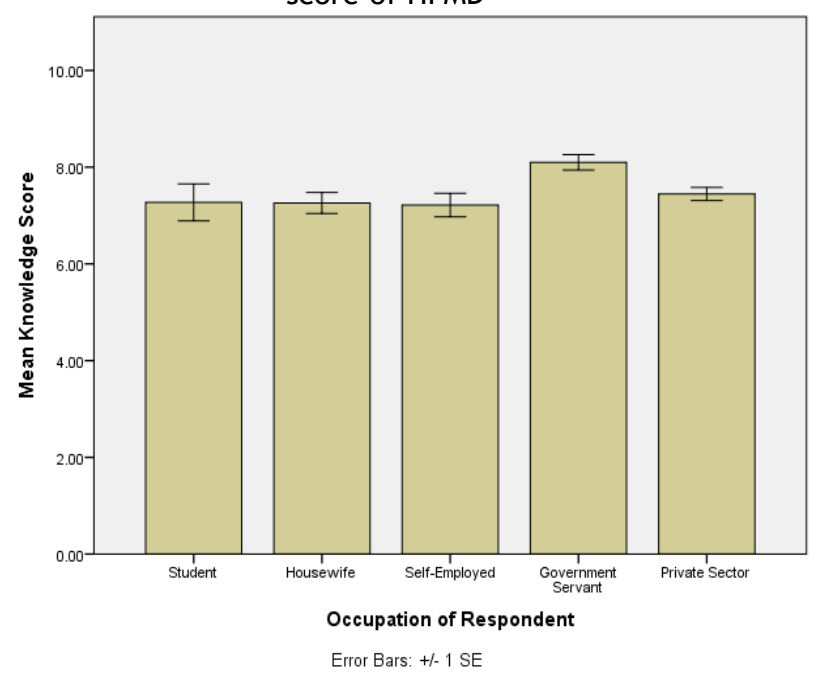

Fig. 2 Influence the respondent's occupation to the knowledge score of HFMD

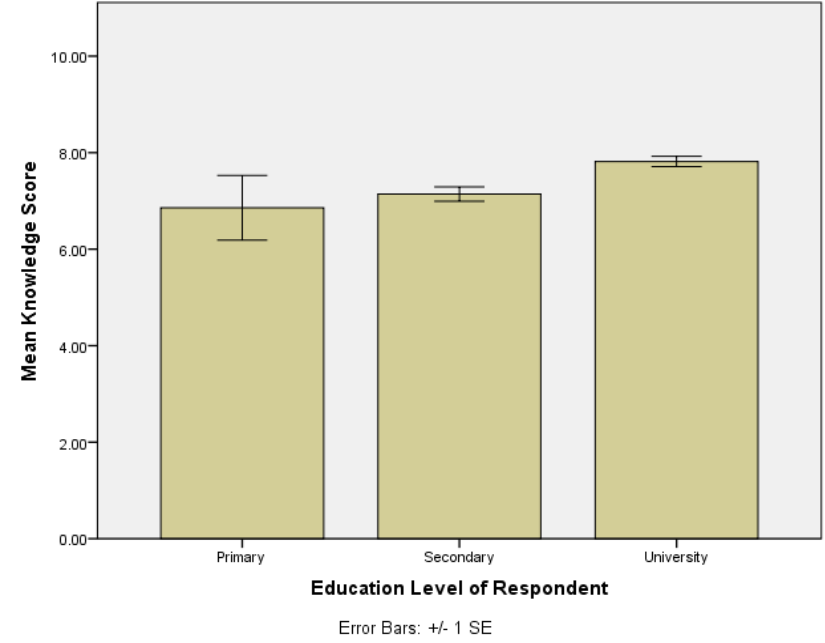

Fig. 3 Influence of respondent's educational level

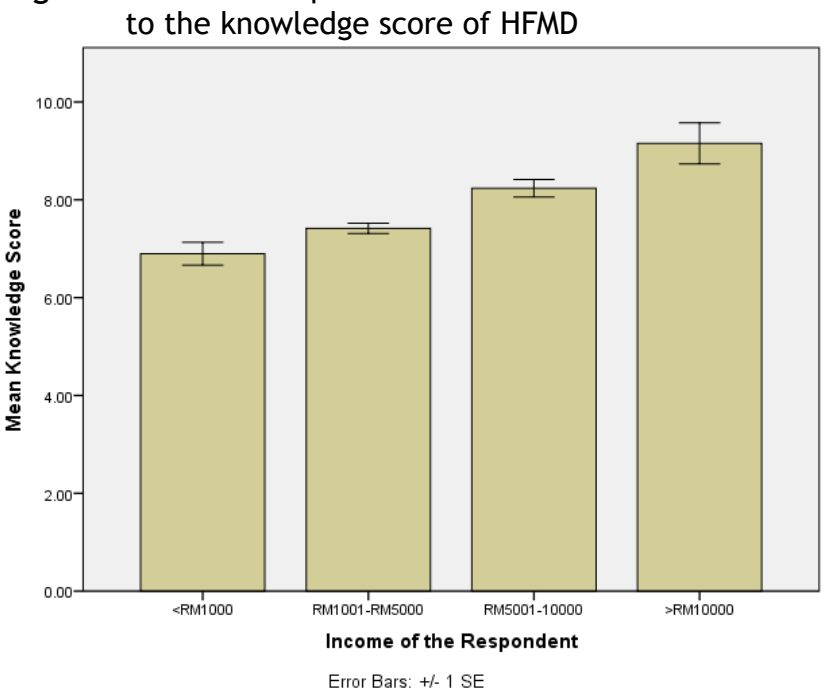

Fig. 4 Influence of respondent's monthly income to the knowledge score of HFMD

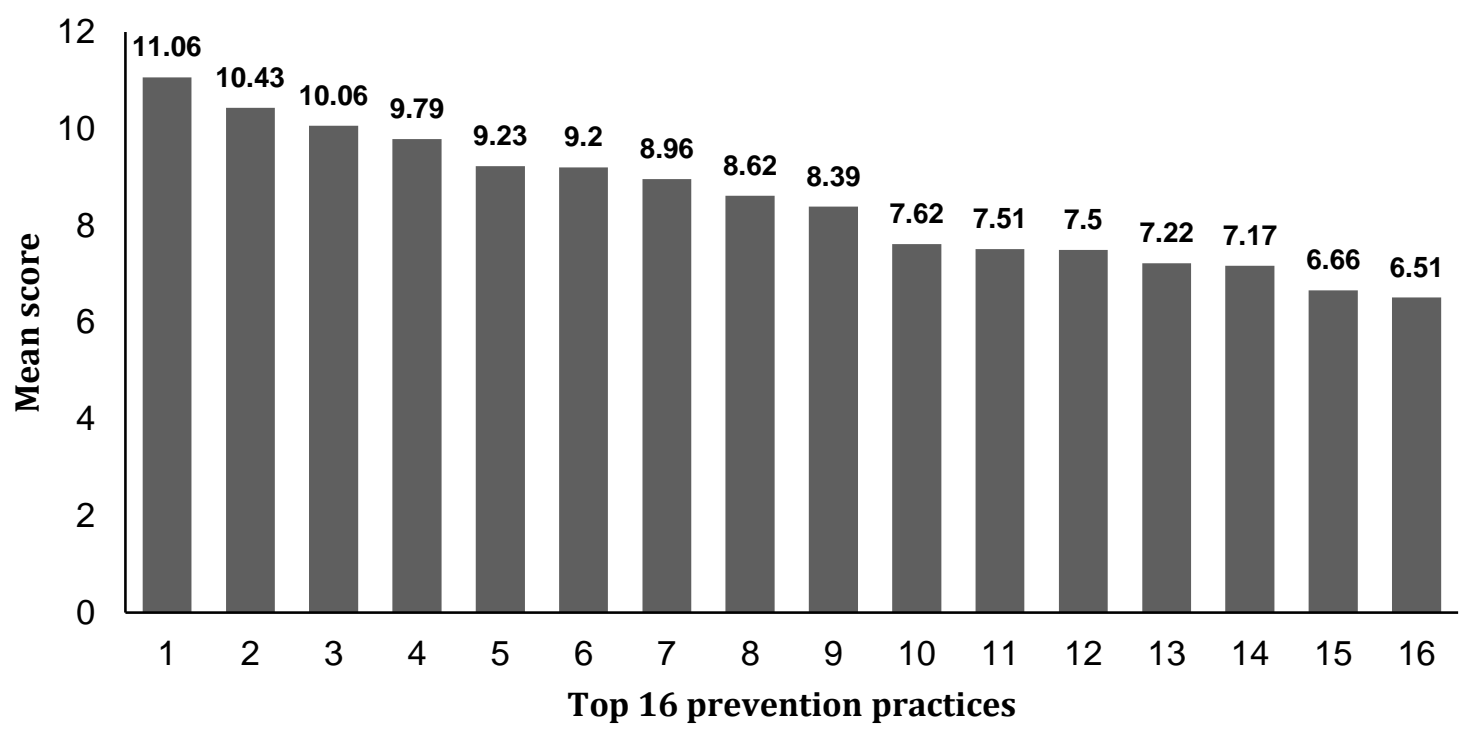

Fig. 5 Top 16 prevention practices towards HFMD

Top 16 prevention practices based on Figure 5 were:

1. I rarely use soap for handwashing

2. I regularly clean children's toys with liquid disinfectant

3. I always rub for at least 20 seconds
4. whenever I wash my hands

5. I rarely clean the table, chair, and floor surfaces

6. I regularly prevent my children from putting stuff into his/her mouth

7. I let my children share the utensils such as 
a cup or spoon with other family members during illness

8. I still send the kids to school during her/his illness

9. I often urge children to wash hands frequently

10. I teach children the indications and correct handwashing steps

11. I always remember to cover my mouth and nose whenever I sneeze or cough

12. I will avoid bringing children to public places during the HFMD outbreak

13. I am concerned if there are any children infected with HFMD in kindergarten/nursery during the outbreak

14. I stay on alert to children's physical health during the HFMD outbreak

15. I always wash my hands after changing child diapers

16. I always wash my hands thoroughly after going to the toilets

17. I wash my hands before feeding my children

\section{DISCUSSION}

Our study showed that the level of knowledge on HFMD is at a moderate level. A study among respondents in nurseries of public universities and residential areas located in Klang Valley showed similar results to our study. ${ }^{8}$ However, a previous study among the visitors of Hospital Tengku Ampuan Afzan, Kuantan, and Pahang showed different results where it was reported at a high level. ${ }^{9}$ These differences might be due to the variation in respondents' geographic area and socio-demographic factors.

Our study showed that few socio-demographic factors; age, occupation, education level, and income, showed some significant association with HFMD. The age of the respondent has some relationship between experience and assessing the information about HFMD. Experience parent influences the level of understanding of children's health care. $^{10}$ Besides that, the education level of the parents and caregivers also affected the knowledge of HFMD. This is because more educated parents may have a better information about the availability and use of health care or have better health behaviour that confers benefits to their children. ${ }^{10}$ Besides that, the parents' occupation also one of the factors that affect the knowledge and understanding of HFMD. Government servant that have obtained a high knowledge score in our study might be related to their unlimited access to health care facilities in Malaysia. They only need to spend at least RM1 for treatment in any government hospital, which in turn encourage them to get a treatment.

Next, the parents and caregivers' income also influenced the level of understanding toward HFMD, where the data from the study confirmed that the higher the income, the higher the awareness and understanding of parents and caregivers toward children's health care. Previous study showed that relationship between children's health and income earned by the family early in the child's life becomes stronger as the child ages. ${ }^{11}$ Parents with lower incomes were less able to maintain their children's health due to the inability to provide proper care. ${ }^{12}$

Our study indicated that the least rehearsed preventive practice was related to handwashing, which were "I wash my hands before feeding my children", "I always wash my hands thoroughly after going to the toilets", "I always wash my hands after changing child diapers" with mean of $6.51,6.66$ and 7.17 respectively. This finding is important to be highlighted as Ruan et al. (2011), Xie et al. (2015), and Zhang et al. (2016) reported that hand hygiene is an importance aspect to prevent HFMD outbreak. ${ }^{12-14}$ These studies also highlighted that and risk infection was highly correlated with increasing the frequency of handwashing, leading to reducing the risk of HFMD infection. ${ }^{12,13,14}$ Based on a randomized controlled trial by Luby et al. (2005), handwashing is also an effective intervention in preventing other infectious diseases, especially for impetigo and diarrhoea. ${ }^{15}$

Besides that, public health prevention measures were still the most practical and effective means of reducing HFMD transmission. ${ }^{16,17}$ According to Xie et al. (2015) and Li et al. (2016), the public playground was one of the main transmission places of HFMD for children and caregivers. ${ }^{13,18}$ This could happen by wiping and touching the surface of playground facilities. Therefore, the regular disinfection of the surface is essential to prevent the virus from being transmitted. ${ }^{13,18}$ From our study, only a few of them aware about this and avoid their children from being in a public place during the HFMD outbreak.

Based on the previous studies, the least rehearsed preventive measures towards HFMD was "regularly cleaning children's toys in the household with liquid disinfectant". 19,20,21,22 This however, was the second most frequent prevention measure practice by parents and caregivers in Bandar Puncak Alam, Selangor. In a study in Thailand, antiseptic usage for cleaning was different depending on the epidemic area. The study reported that in high epidemic areas, a high-quality antiseptic agent was used and the whole centre was closed for a day. Meanwhile, in the low epidemic area, they used chlorine and detergents to clean the area and were closed for two to seven days due to lack of budget. Even though they can use high-quality antiseptic, they do not know the proper technique and how to use these agents. ${ }^{23}$ In our observation, most parents and caregivers have little knowledge of the importance of liquid disinfection in preventing HFMD. In fact, the number of cases of HFMD 
among daycare centres, kindergarten, and preschool can be reduced if the caregivers continue to take note of the importance of using liquid disinfection.

From 16 top preventive practices, we found that seven practices were involved handwashing. According to a systematic review from 16 studies conducted from 2001 to 2011, hand hygiene promotion is one of the most common practice measures. ${ }^{24}$ An intervention study showed that intensive education on hand hygiene could lower down HFMD incidence. ${ }^{25}$ This indicates that an ongoing intervention on hand hygene is critical in order to decrease HFMD among children. Therefore, the first step of children education should emhasize on this measure.

For example, the government can provide incentives to encourage childcare education in childcare facilities. An 'infection control specialists' can be appointed for each facility and be invited to attend regular training workshops about current infectious diseases and provide a forum to exchange ideas and discuss prevention methods.

\section{CONCLUSION}

We found that residences of Bandar Puncak Alam, Selangor have moderate knowledge level on HFMD. This revealed that they are still lacks knowledge and prevention practice toward HFMD. Both parents and caregivers have equal level of knowledge and understanding of HFMD. Although it is at a moderate level, their awareness on prevention practice still inadequate. Therefore, a proper education and health promotion should be conducted regularly to prevent this misconception about HFMD in order to prevent this disease from reoccurring again in the future.

\section{Acknowledgement}

The authors involved in the research would like to thank the residences of Bandar Puncak Alam, Selangor for the cooperation in spending their time to answer the questionnaire given and UiTM Research Ethics Committee for granted ethical approval.

\section{Conflict of interest}

The authors declare no potential conflict of interest.

\section{REFERENCES}

1. CDC. Hand Foot and Mouth Disease । Causes and Transmission | HFMD | CDC [Internet]. CDC. 2017 [cited 2018 Sep 21]. Available from: https: / /www.cdc.gov/hand footmouth/about/transmission.html

2. WPRO. WPRO | Hand, Foot and Mouth
Disease [Internet]. WPRO. WPRO | WHO Western Pacific Region; 2017 [cited 2018 Sep 21]. Available from: http: / /www.wpro.who.int/mediacentre/ factsheets/fs_10072012_HFMD/en/

3. Chan KP, Goh KT, Chong CY, Teo ES, Lau $G$, Ling AE. Epidemic hand, foot and mouth disease caused by human enterovirus 71, Singapore. Emerg Infect Dis 2003; 9(1): 78-85.

4. The Star. HFMD cases exceed warning levels, says ministry. The Star [Internet]. 2018; Available from:

https: / /www.thestar.com.my/news/nati on/2018/07/12/hfmd-cases-exceedwarning-levels-says-ministry

5. Bernama. HFMD outbreak alert in Labuan. New Straits Times [Internet]. 2019 [cited 2019 May 20]; Available from: https: / /www.nst.com.my/news/nation/ 2019/01/451280/hfmd-outbreak-alertlabuan

6. Churchill Edward. A marked increase in HFMD cases this year. The Borneo Post [Internet]. 2019 [cited 2019 May 20]; Available from: https: / /www.theborneopost.com/2019/0 $1 / 25 /$ marked-increase-in-hfmd-casesthis-year/

7. Sample Size Calculator by Raosoft, Inc. [Internet]. [cited 2018 Dec 7]. Available from:

http://www.raosoft.com/samplesize.ht $\mathrm{ml}$

8. Siti Aida SM, Haliza AR. Knowledge, Attitude and Practice towards Hand, Foot and Mouth Disease (HFMD) Among Nursery Governesses in Klang Valley, Selangor. Mal J Med Health Sci 2019. 15(SP4); 40-47

9. Hasnor WN, Othman CN, Che Lamin R. Knowledge, Attitude and Practices Regarding Hand, Foot and Mouth Disease (HFMD) of Visitors in Hospital Tengku Ampuan Afzan, Pahang. TeSSHI "Synergising Transdiscipl Knowl a Sustain Tomorrow" 2012; 1-10.

10. Case A, Paxson C. Parental Behavior and Child Health. Health Aff 2002; 21(2): 16478.

11. Anne C, Darren L, Christina P. Economic Status and Health in Childhood: The Origins of the Gradient. Am Econ Rev 2002; 92(5);1308-34. Available from: http: / /ideas.repec.org/a/aea/aecrev/v9 2y2002i5p1308-1334.html 
12. Ruan F., Yang T., Ma H., Jin Y., Song S., Fontaine R.E., \& Zhu B.P. Risk factors for hand, foot, and mouth disease and herpangina and the preventive effect of handwashing. Pediat. 2011; 127: e898e904.

13. Xie $\mathrm{YH}$, Chongsuvivatwong V, Tan $\mathrm{Y}$, Tang ZZ, Sornsrivichai V, McNeil EB. Important roles of public playgrounds in the transmission of hand, foot, and mouth disease. Epidemiol Infect 2015; 143: 1432-1441.

14. Zhang D, Li Z, Zhang W, Guo P, Ma Z, Chen Q, Du S, Peng J, Deng Y, \& Hao Y. HandWashing: The Main Strategy for Avoiding Hand, Foot, and Mouth Disease. Int J Environ Res Public Health 2016; 13(6); 1 10

15. Luby S.P, Agboatwalla M., Feikin D.R, Painter J., Ward Billhimer MS, Altaf A., \& Hoekstra R.M. Effect of Handwashing on Child Health: A Randomised Controlled Trial. Lancet 2005; 366: 225-233.

16. Hii YL, Rocklov J, \& Ng N. Short Term Effects of Weather on Hand, Foot and Mouth Disease. PLoS ONE. 2011; 6: e16796.

17. Ma E, Wong S, Wong C, Chuang SK, Tsang T. Effects of Public Health Interventions in Reducing Transmission of Hand, Foot, and Mouth Disease. Pediat. Inf. Dis. J. 2011; 30: 432-435.

18. Li P, Li T, Gu Q, Chen X, Li J, Chen X, Chen Y, Zhang D, Gao R, He Z., Zhu X., Zhang W., Hao Y., \& Zhang D. Children ' $s$ Caregivers and Public Playgrounds: Potential Reservoirs of Infection of HandFoot-and-Mouth Disease. Nat Publ Gr. 2016; 6(11); 1-6.

19. Suliman Q, Md Said S, Zulkefli NAM. Predictors of Preventive Practices Towards HFMD among Mothers of Preschool Children in Klang District.
Malaysian J Med Heal Sci. 2017; 13(3): 2132.

20. Lou ML, Lin DJ. Exploration of the Healthy Behaviors Against Enterovirus and Its Related Factors in the Caregivers of Preschool-age Children. J Hung Kuang. 2006; 49: 145-162.

21. Ruttiya C, Tepanata P. Knowledge attitude and preventive behaviors towards hand foot and mouth disease among caregivers of children under five years old in Bangkok, Thai. J. Health Res 2013; 27(5): 281-286.

22. Nguyen TN, Pongjaturawit $Y$, Chaimongkol N. Factors Associated with Maternal Behavior in Prevention of the Hand, Foot and Mouth Disease in Young Children, Vietnam. Thai Pharma and Heal Sci J 2016; 11(1): 33-39.

23. Siriyaporn S, Pilasinee W, Pussadee L, Chandaporn I, Tawatchai A. Effectiveness of HFMD Prevention and Control Measures Between High and Low Epidemic Areas, Northern Thailand. J Health Res 2018; 32(3): 217-28.

24. Joyce HYC, Law CK, Esther $H$, Fung $H$, James R. Best practices to prevent transmission and control outbreaks of hand, foot, and mouth disease in childcare facilities: a systematic review. Hong Kong Med J 2017; 23:177-90

25. Nana G, Huilai M, Jian D, Yanxia M, Liang $H$, Ruiling $G$, Lijie $Z$. Effect of hand washing and personal hygiene on hand food mouth disease: A community intervention study. Medicine 2018; 97(51):1-7 